\title{
VIEWPOINT
}

\section{Diagnostic exercise physiology in chronic heart failure}

\author{
D P Francis, L C Davies, A J S Coats
}

Chronic heart failure (CHF) carries a mortality higher than many forms of cancer, ${ }^{1}$ as well as impairing quality of life and causing many acute hospital admissions. ${ }^{2}$ Despite the recent improvements in medical treatment, prevalence and mortality of CHF seem set to remain high. ${ }^{3}$

The convention of defining $\mathrm{CHF}$ in terms of symptoms, clinical signs, and findings on investigation has certain limitations. Firstly, although the principal symptoms-breathlessness and fatigue on exercise - may be pronounced, they overlap with those of patients with respiratory disease and can even be reported by normal subjects. Secondly, signs of fluid retention do not always persist with optimal medical treatment and when they are found they do not necessarily signify cardiac failure. ${ }^{4}$ Thirdly, while imaging investigations may identify abnormalities in cardiac function at rest, there are difficulties in obtaining an objective, unifying measurement that may be useful across all forms of heart failure. Lastly, none of these observations can identify that exercise capacity is indeed limited by cardiovascular, rather than respiratory, musculoskeletal, or motivational causes.

It may be a weakness of our conventional approach to CHF that abnormalities of exercise performance are gauged only subjectively while objective data are obtained only in the resting state. In this article, we argue that the unifying characteristic in this disease is chronic limitation of exercise aerobic response and that focusing on this may help diagnosis as well as prognostic assessment.

\section{Difficulties with conventional diagnostic techniques}

The New York Heart Association (NYHA) classification of symptoms has served us well as a simple symptom grading system. Training is straightforward and no special equipment is required. However, while it separates patients into asymptomatic, mild, moderate, and severe groups, most patients in routine practice fall into the mild or moderate groups. Psychological factors, in both the patient and the physician, no doubt play an important part in the NYHA grading. Moreover, the sensitivity of this grading to changes in exercise capacity is poor.

Signs of oedema in the limbs or lungs can be evanescent and their interobserver reproducibility and temporal variation are not well established. Leg oedema, in particular, has poor specificity and may have many causes in an elderly population. ${ }^{4}$ Conversely, patients with $\mathrm{CHF}$ receiving regular medical attention may have a very low prevalence of signs of oedema, ${ }^{56}$ despite persistent exercise intolerance and high mortality. To increase its sensitivity, the requirement for oedema might be reduced such that any prior episode is acceptable, although this would reciprocally weaken the specificity.

Objective quantification of left ventricular ejection fraction (EF), although well entrenched in cardiological practice and as an entrance requirement of clinical trials, is not a panacea. $\mathrm{EF}$ is the ratio of stroke volume to end diastolic volume (EDV). Stroke volume is itself equal to cardiac output (CO) divided by heart rate $(\mathrm{HR})$. Thus $\mathrm{EF}=\mathrm{CO} /(\mathrm{HR} \times \mathrm{EDV})$. Since $\mathrm{EF}$ is measured at rest, and at rest $\mathrm{CO}$ of ambulant patients with heart failure is frequently normal, depression of resting EF may be viewed as a manifestation of resting tachycardia or ventricular dilatation.

Even if resting EF may give a complete picture of cardiac systolic function on exercise, it would not simultaneously quantify diastolic heart failure, which is now recognised to carry an adverse prognosis. ${ }^{7-9}$ Indeed, with the inclusion of patients with valvar regurgitation superimposed upon left ventricular disease, the spectrum of CHF includes high, normal, and low EFs. Patients with heart failure resulting from systolic or diastolic dysfunction or valve disease are united by symptoms of fatigue or breathlessness limiting exercise and the common thread in their exercise physiology is chronic limitation of exercise aerobic rate. ${ }^{10}$

The greatest weakness in conventional diagnostic criteria for CHF is that absolutely all the objective evidence collected-by examination or by imaging - is at rest, despite this being a disease of exercise. Exercise abnormalities are addressed solely by subjective questioning; only three levels of symptoms are widely used and those without (or denying) symptoms cannot be separated at all. For most patients consulting physicians for CHF who are in NYHA classes I-III there are no symptoms at rest; to them, there is no doubt that the disease is one of exercise. 
Value of diagnostic exercise physiology Diagnostic exercise physiology ${ }^{11}$ offers several valuable pieces of information to the clinician. Firstly, peak oxygen uptake $\left(\mathrm{VO}_{2}\right)$ is particularly reproducible $\mathrm{e}^{13-15}$ among the available measures of exercise capacity.

Secondly, peak $\mathrm{VO}_{2}$ predicts mortality ${ }^{12} 16-20$ in $\mathrm{CHF}$ better than any resting measurement. This is recognised in guidelines for the management of severe $\mathrm{CHF}$ : a peak $\mathrm{Vo}_{2}$ below $14 \mathrm{ml} / \mathrm{kg} / \mathrm{min}$ implies prognosis poor enough to warrant transplantation. ${ }^{17}$

Thirdly, and arguably clinically most interesting, is its identification of the cause of impaired exercise capacity-specifically, whether it is limitation of exercise aerobic response (characteristic of heart failure ${ }^{11}$ ) or failure to utilise aerobic capacity fully (indicating that cardiac output is not the rate limiting step).

These distinctions are made from the temporal course of metabolism during exercise and measurement of the respiratory exchange ratio of carbon dioxide output $\left(\mathrm{VCO}_{2}\right)$ to $\mathrm{VO}_{2}$. The data in fig $1 \mathrm{~A}$ are from a healthy 60 year old. At rest, $\mathrm{VCO}_{2}$ is less than $\mathrm{VO}_{2}$. As exercise proceeds, $\mathrm{VO}_{2}$ rises but begins to form a plateau; $\mathrm{VCO}_{2}$ continues to rise so that, at peak exercise, the $\mathrm{VCO}_{2}: \mathrm{VO}_{2}$ ratio greatly exceeds 1.00 . This is the simplest of several techniques for confirming the development of anaerobic metabolism.
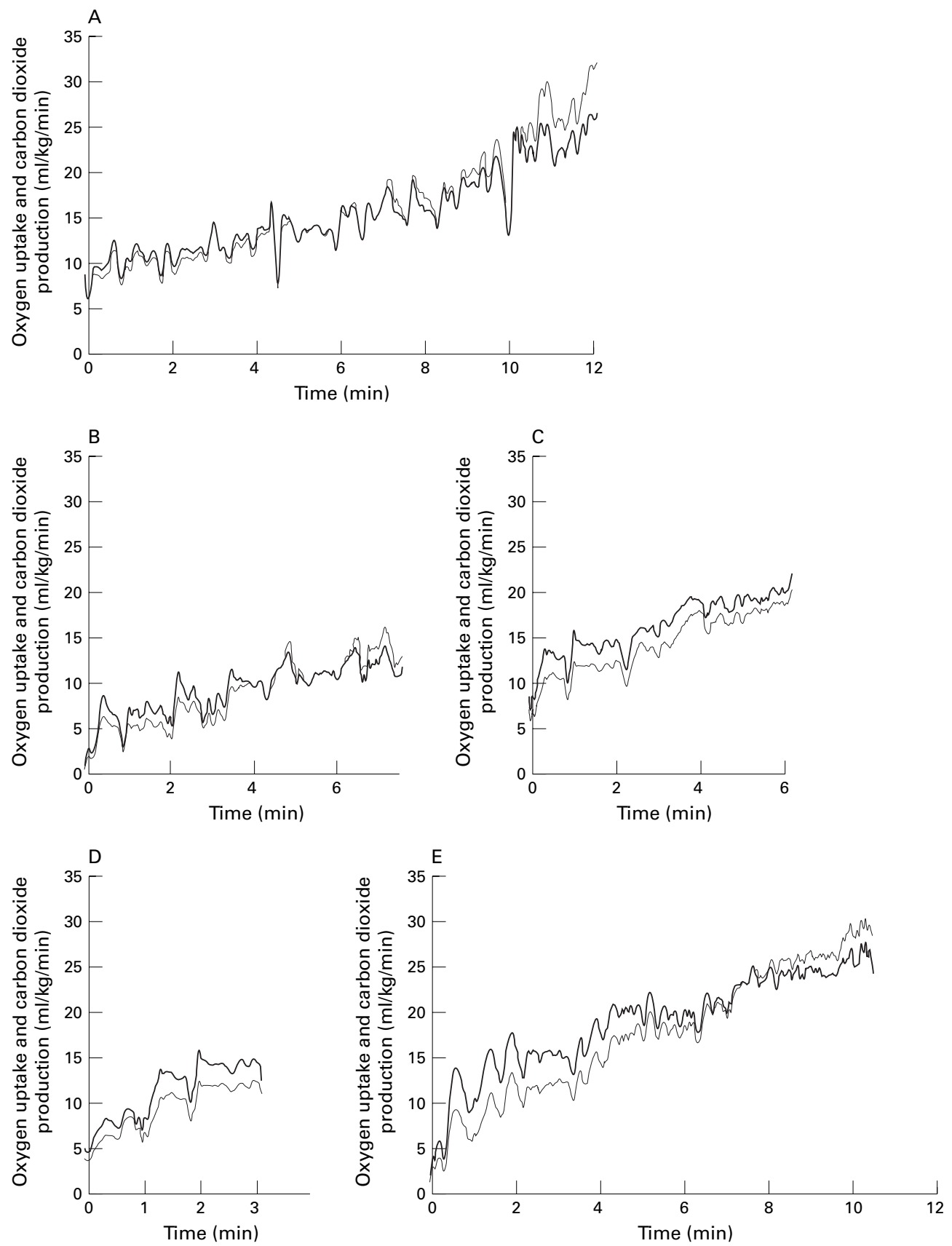

Figure 1 Metabolic traces from diagnostic exercise physiology testing showing oxygen uptake (thick lines) and carbon dioxide production (fine lines). (A) Healthy control. (B) Patient with idiopathic dilated cardiomyopathy: the same pattern, but oxygen uptake is limited at a lower level. (C) Patient with breathlessness, found to be caused by emphysema.

(D) Subject referred with breathlessness, who terminated the test before reaching anaerobic metabolism (but was found to have normal spirometry). (E) Same subject retested, showing normal exercise capacity. 


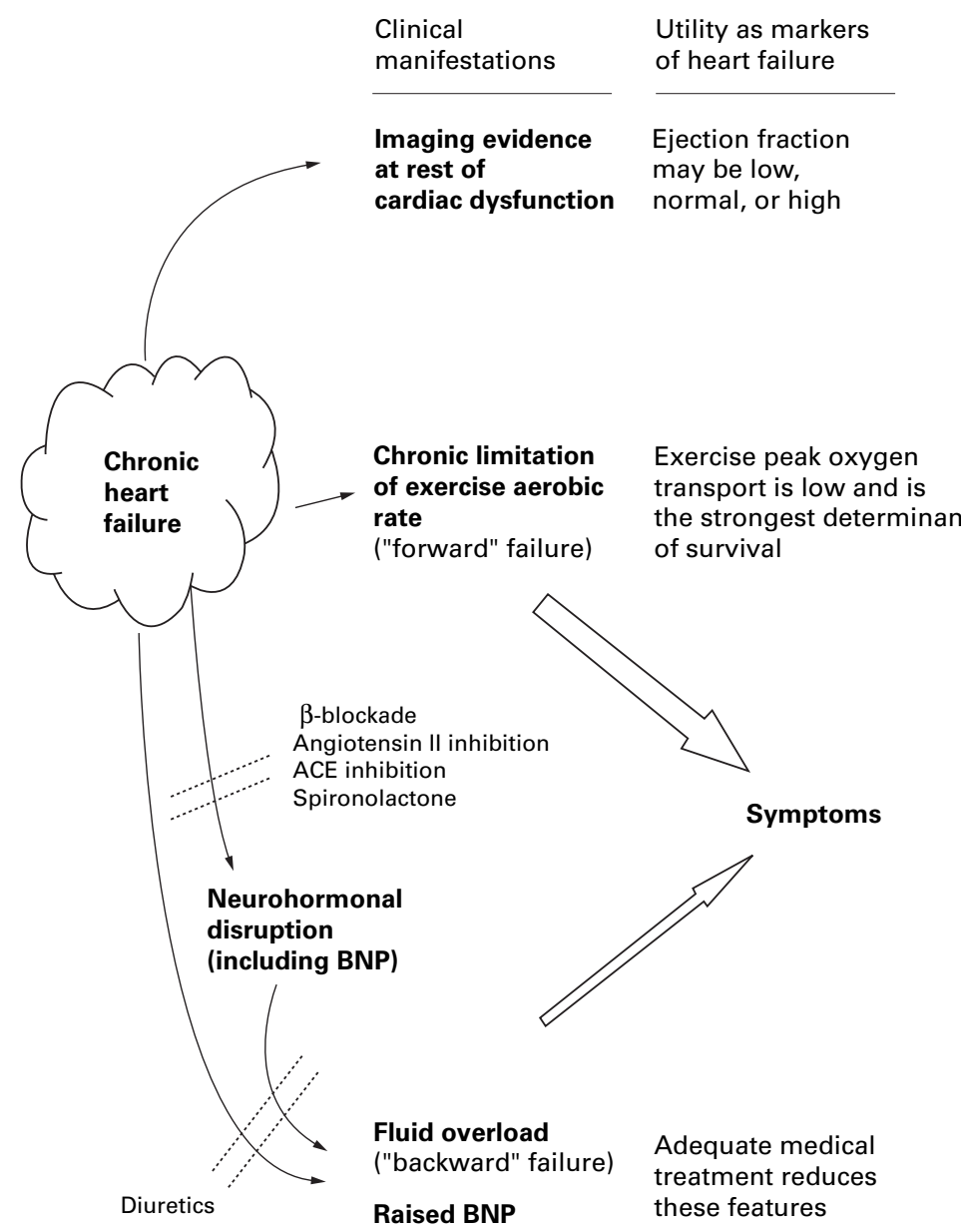

Figure 2 Diagnostic features of chronic heart failure. Ejection fraction may be low, normal, or high. Physical signs of fluid overload are reduced with treatment with diuretics and neurohormonal agents. Chronic limitation of exercise aerobic rate, however, persists. $A C E$, angiotensin converting enzyme; BNP, brain natriuretic peptide.

Figure 1B shows data from a 60 year old with idiopathic dilated cardiomyopathy. At rest, this patient's metabolism closely resembles that of the normal subject, with $\mathrm{VO}_{2}$ of $3.5 \mathrm{ml} / \mathrm{kg} / \mathrm{min}$ and $\mathrm{VCO}_{2}: \mathrm{VO}_{2}$ ratio of 0.80 . Again, as exercise increases, $\mathrm{VO}_{2}$ rises but begins to form a plateau at a much lower level. $\mathrm{VCO}_{2}$ continues to increase and at peak exercise $\mathrm{VCO}_{2}: \mathrm{VO}_{2}$ again exceeds 1.00. This quantitative reduction of the peak achieved $\mathrm{VO}_{2}$ despite development of anaerobic metabolism (chronic limitation of exercise aerobic response) is characteristic of $\mathrm{CHF}$, even when fluid overload has been removed by medical treatment. ${ }^{6}$ Note that for a clinician reviewing this patient, achievement of anaerobic metabolism confirms that the limitation is cardiovascular rather than respiratory or motivational.

In fig $1 \mathrm{C}$, however, although the $\mathrm{Vo}_{2}$ and $\mathrm{VCO}_{2}$ of a 58 year old subject both rise during exercise, breathlessness causes termination before $\mathrm{Vo}_{2}$ plateaus and is overtaken by $\mathrm{VCO}_{2}$. It can be concluded that cardiac performance is not the limiting factor in exercise. (The patient was found to have emphysema on lung function testing.)

The fourth subject was referred for evaluation of breathlessness and chest tightness on exercise. Routine ECG exercise testing showed non-specific ST-T wave changes and coronary angiography was normal. Diagnostic exercise physiology yielded the data in fig $1 \mathrm{D}$, with breathlessness given as the reason for termination. Spirometry was normal and so emphysema was unlikely to be the limiting factor. The subject was therefore reassured and counselled, and re-exercised. This (fig $1 \mathrm{E}$ ) revealed normal exercise capacity.

The fourth useful piece of information that the clinician can obtain is the behaviour of oxygen saturation on exercise. CHF on its own does not cause desaturation on exercise. In one series of 37 patients with $\mathrm{CHF}$, the only three showing desaturation on exercise were found to have alternative diagnoses: patent foramen ovale with right to left shunt during exercise, pulmonary embolic disease, and clinically unsuspected obstructive airways disease. ${ }^{21}$

Fifth, the ventilatory response to exercise (slope of the ratio of expired ventilation to $\mathrm{VCO}_{2}$ ) can be measured. This is abnormally augmented in many patients with $\mathrm{CHF}^{5}$ closely related to symptoms of breathlessness, ${ }^{5}$ and carries additional prognostic significance $^{522}$ that has recently been suggested to be even more powerful ${ }^{23}{ }^{24}$ than that of peak $\mathrm{Vo}_{2}$.

Lastly, alongside these data, all the information obtained from a conventional exercise test is also available, including exercise induced arrhythmias, ${ }^{25}$ ST segment changes, and chronotropic incompetence. ${ }^{26}$ These abnormalities may merit specific treatment.

\section{Practical issues}

There are three principal arguments against shifting the diagnostic focus of CHF from subjective and resting criteria to exercise based criteria. Firstly, the cost of ensuring availability of metabolic monitoring equipment in every district general hospital might be suspected to be prohibitive. However, prices have fallen and now a treadmill with full metabolic monitoring facilities costs little more than a traditional ECG only treadmill. The marginal cost of equipping a clinic for diagnostic exercise physiology is therefore almost zero to a hospital considering routine replacement of (or addition to) its treadmill facility.

The second cloud is the assumption among clinicians who are familiar with ECG only exercise testing but unacquainted with metabolic measurement that it is not possible to distinguish limitation of exercise by heart failure from other causes. However, the central element in diagnostic exercise physiology is measurement of gas exchange-these data allow the distinction to be made.

The third area of concern is over the wisdom of obliging these patients, who may be elderly, to participate in exercise. However, clinical experience is that these tests are safe. In our institution, where diagnostic exercise physiology is routine for heart failure evaluation, we do not consider age or general poor health a contraindication to the measurement of peak $\mathrm{VO}_{2}$. Indeed, our published experience of diagnostic exercise physiology in elderly patients (mean age 76 years) is that our cohort had medium term mortality comparable with that 
of cohorts of elderly patients acutely admitted for heart failure, indicating that they were no less ill. ${ }^{27}$ Moreover, the clinical benefit of exercise therapy in $\mathrm{CHF}$ is becoming clearer ${ }^{28}$; how can we expect patients to heed our calls for regular physical activity at home when we hesitate to offer them a supervised exercise test with full metabolic and electrocardiographic monitoring in a hospital?

\section{The endocrine dimension}

Heart failure is a multisystemic disease with manifestations beyond the cardiovascular system itself. Hormonal disruption is central to the production of fluid overload. Indeed, an increase of brain natriuretic peptide ${ }^{29}$ is sufficiently sensitive and specific to be used as a screening test for heart failure (defined echocardiographically) in a population. ${ }^{30}$ However, while brain natriuretic peptide is likely to become extremely valuable in the identification of potential cases of heart failure, it should be borne in mind that it measures an endocrine phenomenon (fig $2^{2}$ ) that, like fluid overload, becomes less prominent with medical treatment. ${ }^{31}$ Adequately treated patients still have the "forward" component of heart failure, and this continues to be manifested in their exercise physiology.

\section{Conclusions}

$\mathrm{CHF}$ is a disease of exercise: exercise limitation is its principal symptom; the degree of exercise limitation is its principal prognostic indicator. Consequently, it is not surprising that even elementary non-invasive diagnostic exercise physiology assessment gives valuable clinical information. Importantly, exercise limitation by heart failure (fig 1B) can be distinguished from other causes, including poor motivation (fig 1D). Chronic limitation of exercise aerobic response is a reproducible feature of $\mathrm{CHF}$ and correlates well with both symptoms and prognosis. These features appear to commend the objective detection of limitation of the exercise aerobic response as not merely an aspect of CHF but possibly as the unifying and principal concept in this disease (fig 2). Diagnostic exercise physiology can provide this information and can distinguish between the common causes of exercise limitation while remaining simple and becoming increasingly cheap.

1 Stewart S, MacIntyre K, Hole DJ, et al. More malignant than cancer? Five-year survival following a first admission for heart failure in Scotland [abstract]. $7 \mathrm{Am}$ Coll Cardio 2000;35:A551.

2 Garg R, Yusuf F. Epidemiology of congestive heart failure. In: Barnett DB, Pouler H, Francis GS, eds. $C C F$ pathophysiology and treatment. New York: Marcel Dekker, 1993:9-25.
3 Sharpe N, Doughty R. Epidemiology of heart failure and Sharpe N, Doughty R. Epidemiology of heart failure

ventricular dysfunction. Lancet 1998;352(suppl 1):3-7.
Gorman WP, Davis KR, Donnelly R. ABC of arterial and venous disease. Swollen lower limb. BMF 2000;320:1453 6.

5 Chua TP, Ponikowski P, Harrington D, et al. Clinical correlates and prognostic significance of the ventilatory response to exercise in CHF. 7 Am Coll Cardiol 1997;29:1585-90.

6 Anker SD, Ponikowski P, Varney S, et al. Wasting as independent risk factor for mortality in CHF. Lancet 1997; 349:1050-3.

7 Pinamonti B, Di Leonarda A, Sinaga G, et al. Restrictive LV filling pattern in dilated cardiomyopathy assessed by doppler echo. F Am Coll Cardiol 1993;22:808-15.

8 Taffet GE, Teasdale TA, Bleyer AJ, et al. Survival of elderly men with CHF. Age Ageing 1992;21:49-55.

9 Setaro JF, Soufer R, Remetz MS, et al. Long-term outcome in patients with $\mathrm{CHF}$ and intact systolic left ventricular performance. Am F Cardiol 1992;69:1212-6.

10 Kitzman DW, Higginbotham MB, Cobb FR, et al. Exercise intolerance in patients with heart failure and preserved left ventricular systolic function. $f \mathrm{Am}$ Coll Cardiol 1991;17: 1065-72.

11 Weber KT, Kinasewitz GT, Janicki JS, et al. Oxygen utilization and ventilation during exercise in patients with CCF. Circulation 1982;65:1213-23.

12 Mancini DM, Eisen H, Kussmaul W, et al. Value of peak exercise oxygen consumption for optimal timing of cardiac transplantation in ambulatory patients with heart failure. Circulation 1991;83:778-86.

13 Elborn JS, Stanford CF, Nicholls DP. Reproducibility of cardiopulmonary parameters during exercise in patients with CCF. Eur Heart f 1990;11:75-81.

14 Dickstein K, Barvik S, Aarsland T, et al. Reproducibility of cardiopulmonary exercise testing in men following myocardial infarction. Eur Heart $\mathcal{f} 1988 ; 9: 948-54$.

15 Cohen-Solal A, Benessiano J, Himbert D, et al. Ventilatory threshold during exercise in patients with mild to moderate CHF. Int $\mathcal{f}$ Cardiol 1991;30:321-7.

16 Van den Broek S, Van Veldhuisen D, De Graeff P, et al. Comparison between NYHA classification and peak oxygen consumption in the assessment of functional status and prognosis in patients with mild to moderate CHF. Am f Cardiol 1992;70:359-63.

17 Mudge GH, Goldstein S, Addonizio LJ, et al. 24th Bethesda conference taskforce. F Am Coll Cardiol 1993;22:21-31.

18 Szlachcic J, Massie BM, Kramer BL, et al. Correlates and prognostic implication of exercise capacity in CHF. $A m \mathcal{F}$ Cardiol 1985;55:1037-42.

19 Chomsky DB, Lang CC, Rayos GH, et al. Hemodynamic exercise testing: a valuable tool in the selection of cardiac exercise testing: a valuable tool in the selection of cardiac

20 Opasich C, Pinna GD, Bobbio M, et al. Peak exercise oxygen consumption in CHF: toward efficient use in the individual patient. F Am Coll Cardiol 1998;31:766-75.

21 Clark AL, Coats AJ. Usefulness of arterial blood gas estimations during exercise in patients with CHF. Br Heart 7 $1994 ; 71: 528-30$

22 Robbins M, Francis G, Pashkow FJ, et al. Ventilatory and heart rate responses to exercise. Circulation 1999;100: 2411-7.

23 Francis DP, Shamim W, Davies LC, et al. Cardiopulmonary exercise testing for prognosis in CHF. Eur Heart f 2000;21: 154-61.

24 Kleber FX, Vietzke G, Wernecke KD, et al. Impairment of ventilatory efficiency in heart failure: prognostic impact. Circulation 2000;101:2803-9.

25 Cohen-Solal A, Aupetif JF, Page E, et al. Transient fall in oxygen intake during exercise in CHF. Chest 1996;110: $841-4$.

26 Lauer MS, Francis GS, Okin PM, et al. Impaired chronotropic response to exercise stress testing as a predictor of mortality. FAMA 1999;281:524-9.

27 Davies LC, Francis DP, Piepoli M, et al. CHF in the elderly: value of cardiopulmonary exercise testing in risk stratification. Heart 2000;83:147-51.

28 Piepoli MF, Flather M, Coats AJ. Overview of studies of exercise training in CHF. Eur Heart f 1998;19:830-41.

29 Cowie MR, Struthers AD, Wood DA, et al. Value of natriuretic peptides in assessment of patients with possible new heart failure in primary care. Lancet 1997;350:1349-53.

30 McDonagh TA, Morrison CE, Lawrence A, et al. Symptomatic and asymptomatic left-ventricular systolic dysfunction in an urban population. Lancet 1997;350:829-33.

31 Troughton RW, Frampton CM, Yandle TG, et al. Treatment of heart failure guided by plasma aminoterminal BNP concentrations. Lancet 2000;355:1126-30. 